\title{
Contaminants and heavy metals along the mangrove area of Dongzhai Harbor, China: distribution and assessment
}

\author{
Jing Liu ${ }^{1,2} \cdot$ Thiri Myat ${ }^{2,3}$ \\ Received: 7 February 2021 / Accepted: 13 September 2021 \\ Published online: 29 September 2021 \\ (c) The Author(s) 2021 OPEN
}

\begin{abstract}
In recent decades, higher-place shrimp ponds are prevalent in coastal areas of developing countries. However, shrimp aquaculture has a growing negative impact on mangrove wetland ecosystems. Mangroves located in Dongzhai harbor are under threat continuously of this commercialization. Therefore, a comprehensive analysis of contaminants and heavy metals is necessary for Dongzhai harbor, considering the mangrove area was declined and ecological services offered to the coastal communities with an insight for future restoration activities. In this study, pond effluents (Total Nitrogen (TN), Ammonia Nitrogen (AN), Total phosphorus (TP), Chemical Oxygen Demond (COD)) and heavy metals (Cd, $\mathrm{Cu}, \mathrm{Pb}, \mathrm{Zn}$ ) were monitored in Dongzhai harbor yearly between 2013 and 2017. The results showed that the contents of $\mathrm{Cd}, \mathrm{Cu}, \mathrm{Pb}$, and $\mathrm{Zn}$ were far lower than the standards. However, the main contaminants were organic matter and nitrogen. Maximum values of COD and TN were $26.10 \mathrm{mg} \cdot \mathrm{L}^{-1}$ and $1.34 \mathrm{mg} \cdot \mathrm{L}^{-1}$, respectively in 2017 . Single factor index, Nemerow's pollution index, and Trophic level index revealed that the heavily polluted areas were Tashi and Sanjiang town.
\end{abstract}

Keywords Dongzhai harbor $\cdot$ Pollution monitoring $\cdot$ Analysis and assessment $\cdot$ Mangrove

\section{Introduction}

Mangroves are tropical and subtropical highly productive coastal ecosystems, which are found within the intertidal areas [1, 2]. Mangroves can provide numerous food, wood, medicine, fuel and other goods or services, which is absolutely important to human and society $[3,4]$. In addition to providing numerous avian and aquatic species with suitable habitats, mangrove wetland ecosystems can protect coastal areas from tsunamis, hurricanes, tropical cyclones, and other natural disasters $[3,5]$. Despite the well understood significance of mangroves, during the past semicentury, the mangroves began to die in large numbers and the ecosystems faced serious threats, especially in the developing countries [6]. There are a lot of deforestation and degradation in the mangroves because of the pressure of land use competition. Brackish aquaculture, salt production, and agriculture are the man-made causes of mangrove loss [7, 8]. Additionally, global warming, tropical cyclones, tsunamis, and other natural disturbances have contributed to mangrove loss $[9,10]$. However, mangrove ecosystems are more resilient to natural disturbances than to human-induced disturbances.

In recent years, the increasing demand for shrimp around the world led to an explosive expansion of shrimp farming, especially in tropical coastal areas [11, 12]. However, shrimp aquaculture has a growing negative impact on mangrove wetland ecosystems. A large portion of shrimp feed added to the shrimp pond cannot be completely transformed into biomass, which can

Thiri Myat, 1486447086@qq.com | ${ }^{1}$ Biology Research Department, School of Caoqiao, Suzhou 215031, China. ${ }^{2}$ Space and Environment Department, Beihang University, Beijing 100191, China. ${ }^{3}$ Biotechnology Research Department, Mandalay Division, Ministry of Education, Kyauk Se 15011, Republic of the Union of Myanmar. 
be responsible for excess primary productivity, and even causes eutrophication of water bodies $[11,13]$. Therefore, temporal and spatial assessment of contaminants in shrimp farming areas is necessary to protect the mangrove ecosystems.

The Dongzhai harbor is a representative zone with a thirty-year history of mariculture in China. It is also the main area of mangrove distribution in China. In this area, shrimp farms use the higher-place pond. This is a kind of aquaculture pond, which is built above the high tide line [14]. In the process of shrimp farming, the aquaculture water in the pond needs to be raised by the power so that the breeding process is unaffected by the tide. Because the bottom of the pond is higher than the sea level, it can easily discharge the organic pollutants such as the residual bait and the shrimp feces. This factor can control the water quality in ponds easily and increase the success rate of shrimp culture [15]. This farming method has brought huge economic benefits to local residents. However, the development of coastal shrimp farming has caused serious pollution. Mangrove area was threatened and declined throughout the Dongzhai harbor, which was decreased nearly $11 \%$ from 1990 to 2010 (the Bureau of Statistics of Hainan Province, http:// www.stats.hainan. gov.cn/) [16]. Furthermore, the annual growth rate of the degraded area of mangroves was 66.4\% from 2010 to 2013 in Dongzhai harbor. The major mangrove wood-boring isopod was Sphaeroma terebrans. The mangrove were damaged by borers, which was distributed in the coastal areas suffering serious anthropogenic disturbance and contamination. Shrimp culture made the water eutrophic, which could provide $S$. Terebrans with sufficient food $[15,17,18]$. Hence, the pollution indicators (Total Nitrogen, Ammonia Nitrogen, Total Phosphorus, Chemical Oxygen Demand) related to aquaculture wastewater were monitored. Based on monitoring indicators, the study compared the monitored concentrations of pollutants in the water with the standard values, to determine the pollution exceeding multiples based on Single factor index, and analyzed pollution stress by Nemerow's pollution index (NPI) and determined eutrophication by Trophic level index (TLI). Additionally, heavy metal pollution is a serious threat to the marine ecological environment due to its high toxicity, non-degradability, and bioaccumulation. Marine sediment is a large reservoir for heavy metals, thus monitoring heavy metals in the coastal areas is considered as an approbatory approach for environmental assessment $[19,20]$. In recent years, urbanization of surrounding cities and the construction of shrimp ponds increase the potential risk of heavy metals to seafood security and ecological environment in Dongzhai harbor. Thus, whether the ecological environment in Dongzhai harbor is polluted by heavy metals needs to be investigated.
Even though, aquaculture contamination in Dongzhai harbor has been reported, the mangrove habitats have not been comprehensively evaluated. Whether the environment of Dongzhai harbor is polluted by aquaculture wastewater needs to be investigated so as to assess their potential risk to the mangrove ecosystem. The study was designated to examine the pollution status, spatiotemporal variation, pollution sources and potential risks of pollution indicators in coastal water (TN, AN, TP, $C_{\mathrm{Mn}}$ ) and sediment $(\mathrm{Cd}, \mathrm{Cu}, \mathrm{Pb}, \mathrm{Zn}, \mathrm{pH})$, via analyzing the monitoring data in Dongzhai harbor of Hainan yearly, 2013-2017. Single factor index, Nemerow's pollution index, and Trophic level index were used to analyze the contamination of mangrove areas.

\section{Material and methods}

\subsection{Study area}

Hainan is located in the south of China. With a tropical monsoon climate, an extensive coastline, the vast water resources, the annual warmed, the abundant rainfall and numerous intertidal bay areas, Hainan provides suitable environmental conditions for mangrove growth. Hainan Island belongs to a tropical monsoon marine climate which has the following features: distinct seasons, no extreme hotness in summer, no extreme coldness in winter, slight annual temperature differences, and high annual average temperature. With a wide range of tropical plants, flowers, fruits, and herbs, Hainan is one of the largest tropical gene banks in Asia [21, 22].

Dongzhai Harbor is located in the northeast of Hainan Province $\left(19^{\circ} 51^{\prime} \sim 20^{\circ} 1 \mathrm{~N}, 110^{\circ} 32^{\prime} \sim 110^{\circ} 37^{\prime} \mathrm{E}\right)$, which is belonging to the Qiongzhou Strait (Fig. 1). Mangrove preserved in DongZhai harbor is the largest coastal forest in China and a treasure house of species and genes with 16 families and 32 species of mangrove plants, 204 species of birds, 115 species of mollusks, 119 species of fish, 70 species of crabs, and 40 species of shrimps [23]. In 2010, the total mangrove area of Dongzhai harbor was about 1578.2 ha and the mangrove species mainly include Rhizophora stylosa, Avicennia marina, Sonneratia apetala, Sonneratia caseolaris, Kandelia candel, Bruguiera sexangula, and Ceriops tagal [24].

\subsection{Sampling}

The study conducted a thorough investigation of water and sediment pollution in Dongzhai harbor, Hainan. The sampling range is located in the west and south of Dongzhai harbor, which is the main distribution area of mangroves and shrimp ponds in Hainan. The fifteen points 


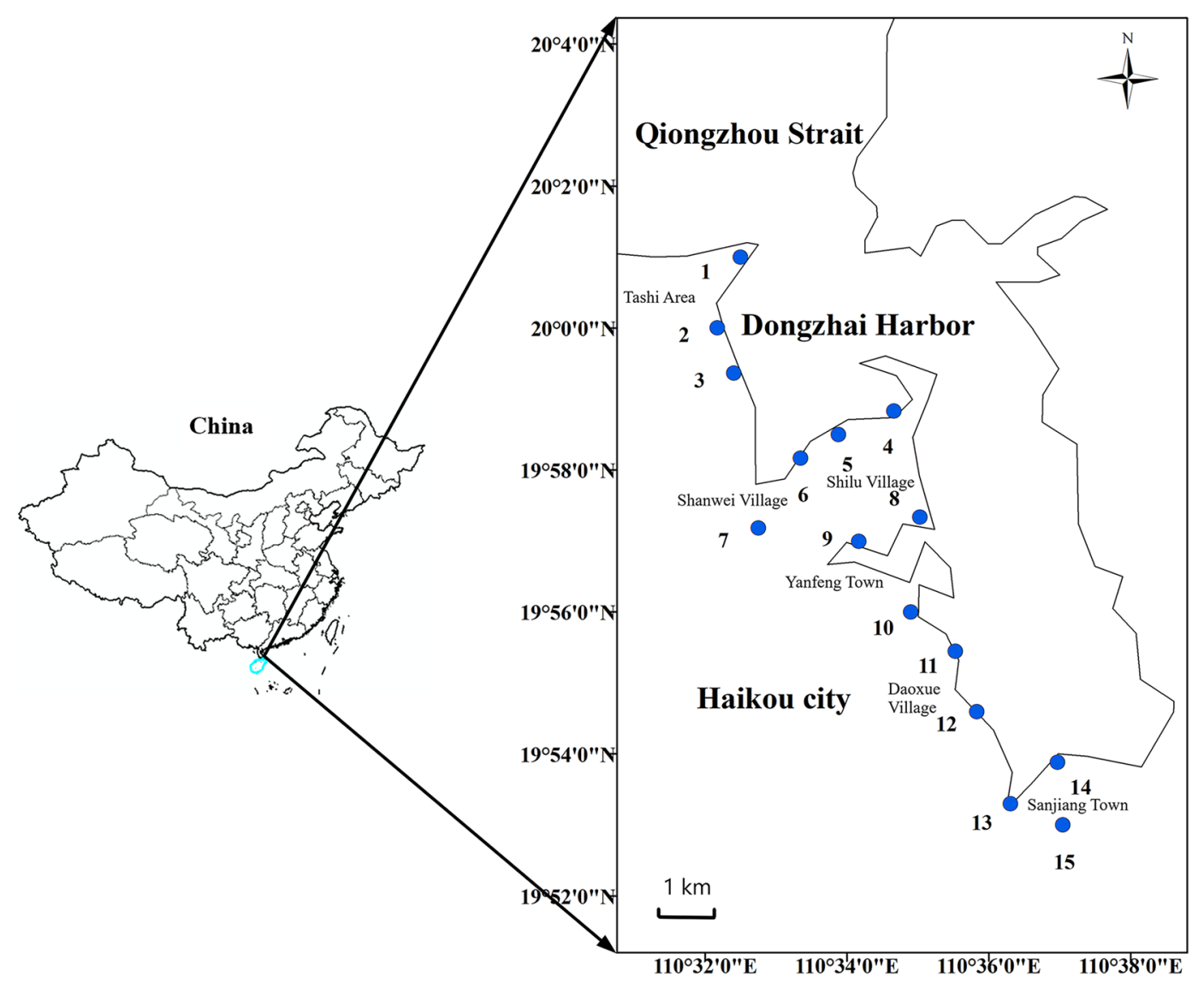

Fig. 1 Maps of the study area. Map of China, including the entire Hainan province and Dongzhai harbor. Blue circle symbols (1-15) represent sampling stations that were investigated during February and August yearly from 2013 to 2017

were separately located at six sampling areas. According to the location of the pollution source and the actual topography, these points are all located $25-30 \mathrm{~m}$ away from shrimp ponds and 1-2 $\mathrm{m}$ away from mangroves. Circumstances around sampling points, for example, the density of mangroves, topography of intertidal zone, and the number of shrimp ponds are similar in the same area. Fifteen sampling points were set up along Dongzhai harbor (Fig. 1) during the monitoring process.

Sample collection was launched in February and August (dry and wet season) from 2013 to 2017, which had the average temperatures of $18.8^{\circ} \mathrm{C}$ and $28.1 \mathrm{oC}$, respectively and total precipitation of $30.6 \mathrm{~mm}$ and $171.9 \mathrm{~mm}$, respectively. The samples were collected in low tide period, which could assess the anthropogenic effects. Due to high tide, the seawater dilution effect would affect the monitoring results. Water samples for chemical measurements were collected and preserved in printed polyethylene bottles with sulfuric acid (to $\mathrm{pH}$ 2.0) [25]. The polyethylene bottles were stored at $4{ }^{\circ} \mathrm{C}$ in the dark temperature controlled containers while in transit to the laboratory on the same day, which was carried out seven days or less after sampling. All the chemical analyses were done according to standard methods (American Public Health Association (APHA), 1992). At each sampling point, sediment samples were collected by stripping the surface sediment from 2 to $3 \mathrm{~cm}$ with a sampling shovel firstly and then using polyvinyl chloride core samplers (about $500 \mathrm{~g}$ weight, $20 \mathrm{~cm}$ depth). Every sample was transferred into a prelabeled clean plastic bag and the transportation was same as water sample [26].

For water samples, $\mathrm{COD}_{\mathrm{Mn}}$ was determined by acidic potassium permanganate titration. Concentrations of TN and TP were determined by persulfate digestion. The concentration of AN was determined by Nessler's reagent colorimetric method. For sediment samples, the metal content was obtained through acid digestion $\left(\mathrm{HNO}_{3}: \mathrm{HClO}_{4}: \mathrm{HF}=5: 4: 1\right.$, in volume) and the contents of $\mathrm{Cd}$, $\mathrm{Cu}, \mathrm{Pb}$, and $\mathrm{Zn}$ were determined by Inductively Coupled Plasma Mass Spectrometry (ICP-MS, PerkinEImer NexION $350 \mathrm{X}, \mathrm{USA}$ ). The $\mathrm{pH}$ value of sediment was determined by the extraction method with $0.01 \mathrm{~mol} / \mathrm{L}$ calcium chloride solution (ISO 10390:2005) Figs. 2 and 3. 

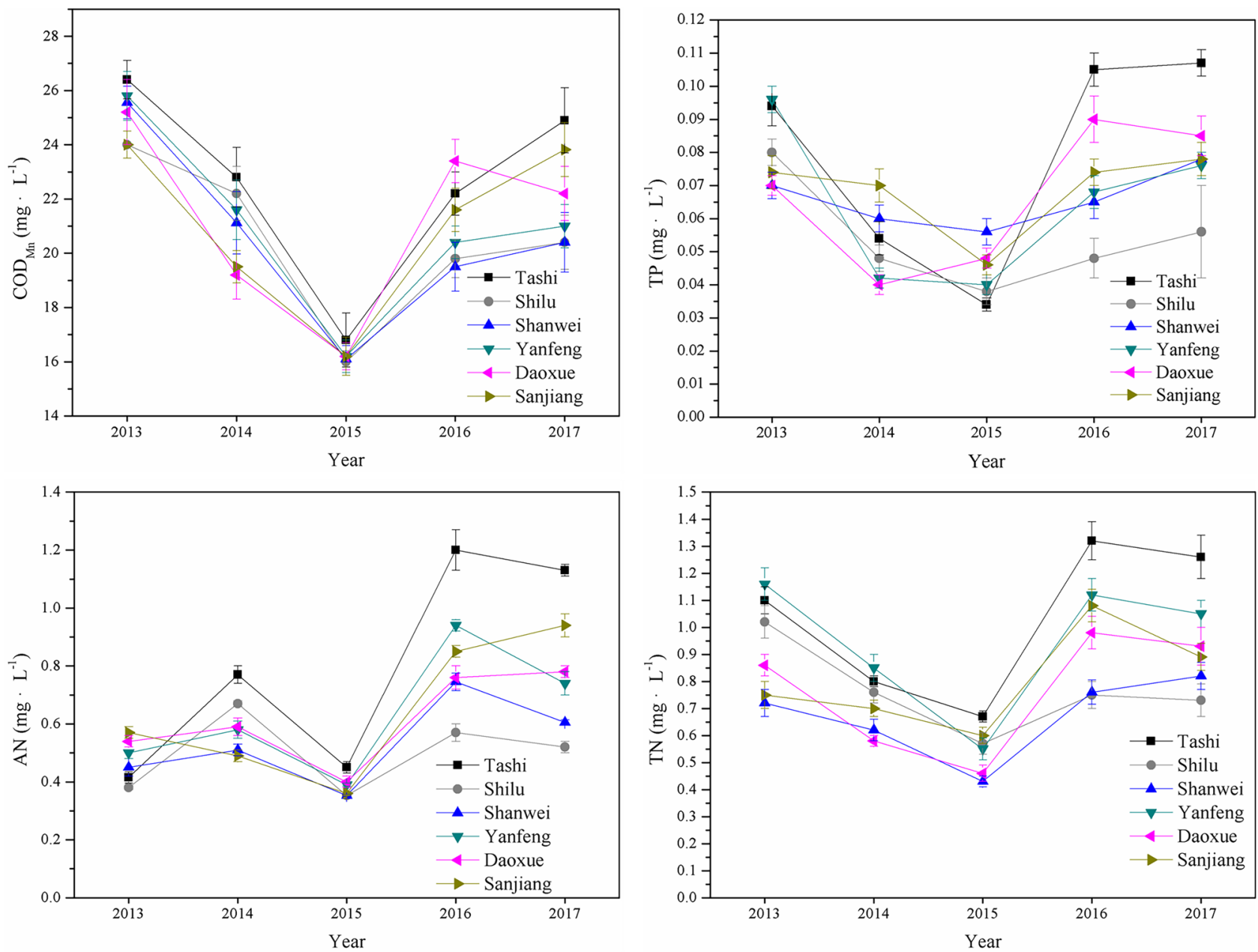

Fig. 2 Temporal variations in contents of $C D_{M n}, T P, T N$ and $A N$ in water samples along the Weihai coast during February and August from 2013 to 2017. The data represent average values \pm the stand-

ard deviation during different years; the bars represent the standard deviations of values from different stations in the study area of each year

Based on the monitoring data and ecological investigation of mangrove areas in Dongzhai harbor, the study used Single factor index, Nemerow's pollution index (NPI), and Trophic level index (TLI) to evaluate the pollution level of mangrove areas.

\subsubsection{Single factor index}

Single factor index is used to compare the measured concentration of pollutants with the environmental standard values to determine the pollution exceeding multiples. Currently, the single factor index of Dongzhai harbor is calculated using the following equation.

$P_{i, j}=\frac{C_{i, j}}{S_{i}}$

where $P_{i, j}$ is the Single factor index of pollutant $i$ at the $j$ sampling point, which means the exceeding standard multiple. $C_{i, j}$ represents the monitored concentration of the pollutant $i$ at the $j$ sampling point. $S_{i}$ represents the standard concentration of the pollution factor $i$. In this study, $S_{i}$ is the Environmental Quality Standard for Surface Water, China (Table 1).

Water quality requirements are divided into five classes according to its purpose for use and protection target.

Class I: mainly for source of water and national nature protection areas;

Class II: mainly for the first class protection areas for centralized potable water source, protection areas for rare fishes, spawn ground for fishes and shrimps, etc.

Class III: mainly for the second class protection areas for centralized potable water source, protection areas for 

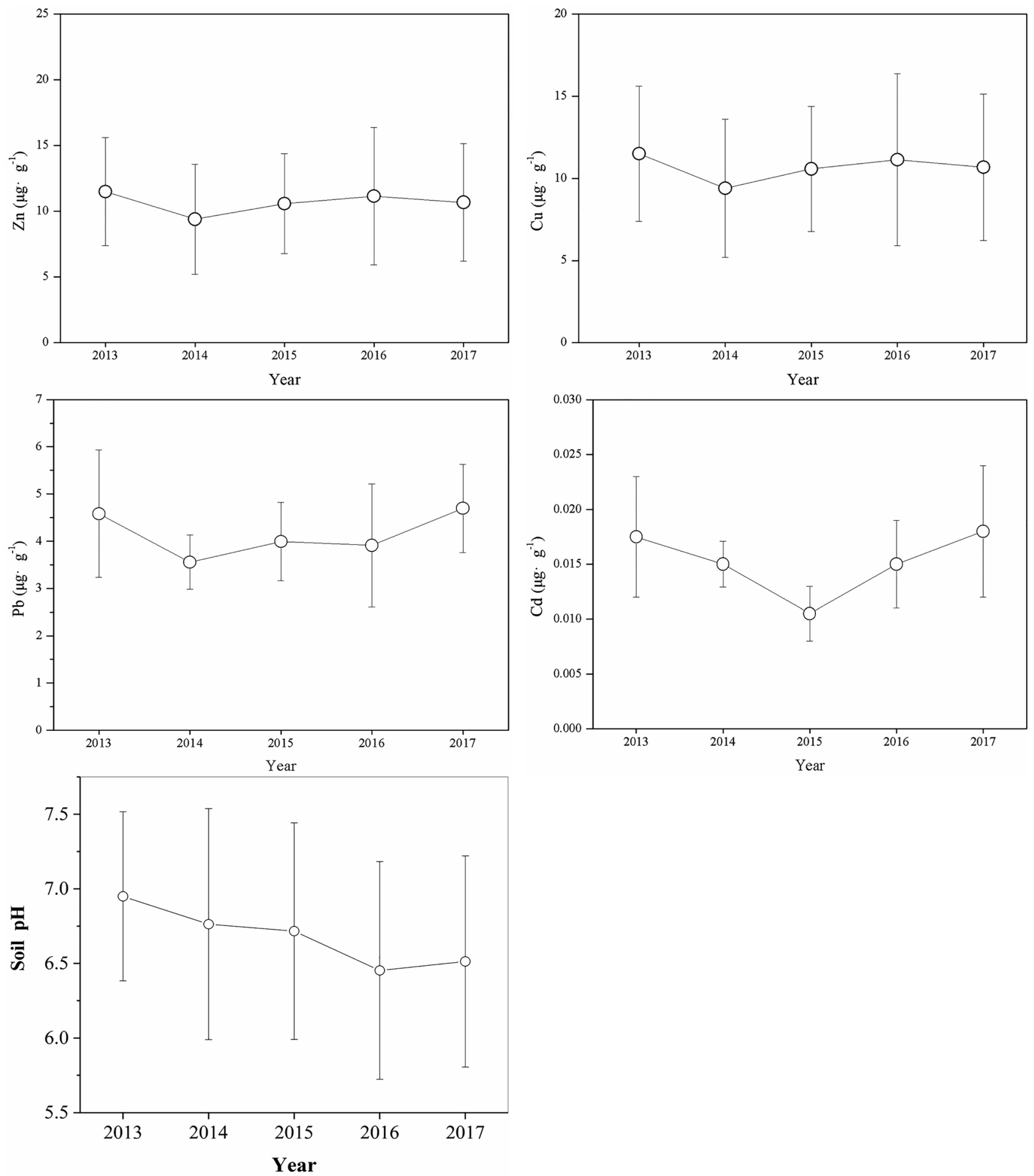

Fig. 3 Temporal variations in contents of $\mathrm{Cu}, \mathrm{Pb}, \mathrm{Zn}, \mathrm{Cd}$ and $\mathrm{pH}$ in soil samples along the Weihai coast during February and August from 2013 to 2017 . The data represent average values \pm the stand-

ard deviation during different years; the bars represent the standard deviations of values from different stations in the study area of each year

general fish and shrimp overwintering field, migratory passage, aquaculture area and other fishery waters and swimming areas.

Class IV: mainly for general industrial water areas and entertainment water areas not directly touched by body. 
Table 1 Environmental Quality Standard for Surface Water

\begin{tabular}{llllll}
\hline Classification Standard value items & Class I & Class II & Class III & Class IV & Class V \\
\hline Total phosphor $\leq$ & 0.02 & 0.1 & 0.2 & 0.3 & 0.4 \\
Ammonia nitrogen $\leq$ & 0.15 & 0.5 & 1.0 & 1.5 & 2.0 \\
Total nitrogen $\leq$ & 0.2 & 0.5 & 1.0 & 1.5 & 2.0 \\
Permanganate index $\leq$ & 2 & 4 & 6 & 10 & 15 \\
\hline
\end{tabular}

Class V: mainly for farmland water areas and water areas for general landscape requirement.

Mangrove wetland in Dongzhai harbor, Hainan is belong to the Class III standard.

\subsubsection{Nemerow's pollution index (NPI)}

Nemerow's pollution index (NPI) is representative of the comprehensive pollution index. It can directly and intuitively reflect the comprehensive water quality in the monitored area. It can not only highlight the influence of the heaviest pollution factors but also consider the other factors. Meanwhile, NPI avoids the influence of subjective factors in the weight coefficient during the weighting calculation [27]. Currently, the NPI of Dongzhai harbor is calculated using the following equation.

$P I_{j}=\sqrt{\frac{\left(\operatorname{Max} \frac{C_{i, j}}{S_{i}}\right)^{2}+\left(\frac{1}{n} \sum_{i=1}^{n} \frac{C_{i j}}{S_{i}}\right)^{2}}{2}}$

where $\mathrm{PI}_{\mathrm{j}}$ is the Nemerow's pollution index at the $\mathrm{j}$ sampling point. $C_{i, j}$ represents the actual concentration of the pollutant $i$ at the $j$ sampling point. $S_{i}$ represents the standard concentration of the pollution factor $i$. The obtained PI j was generally classified into five grades: $\mathrm{PI}_{j}<1$ indicates unpolluted for the assessed area, $1<\mathrm{PI}_{j}<2$ suggests the mild of contamination, $2<\mathrm{PI}_{\mathrm{j}}<3$ indicates moderate pollution and $\mathrm{PI}_{\mathrm{j}}>3$ represents severe pollution.

\subsubsection{Trophic level index (TLI)}

Trophic level index (TLI) is a comprehensive index that can characterize the eutrophication level of water bodies $[28,29]$. Currently, the TLI of Dongzhai harbor is calculated using the following equations.

$T L I\left(\sum\right)=\sum_{j=1}^{m} w_{j} \cdot T L I_{j}$

$W_{j}=\frac{r_{i j}^{2}}{\sum_{i=1}^{m} r_{i j}^{2}}$
Table 2 Correlation coefficient of TLI

\begin{tabular}{llll}
\hline & TP & TN & COD $_{\mathrm{Mn}}$ \\
\hline$r_{i j}$ & 0.84 & 0.82 & 0.83 \\
$r_{i j}^{2}$ & 0.7056 & 0.6724 & 0.6889 \\
$W_{j}$ & 0.34 & 0.33 & 0.33 \\
\hline
\end{tabular}

where $T L I_{j}$ is the $j$ th indicator with the corresponding weight $\mathrm{W}_{\mathrm{j}}$. According to the relationship between the reference chlorophyll $a$ concentration and every indicator, the correlation coefficients of $r_{i j}$ value were given in Table 2. The TLI of all the monitoring points was calculated from total phosphorus, total nitrogen and chemical oxygen demand. The formulas of each TLI indicator are given below:

$\operatorname{TLI}(T P)=10(9.436+1.624 \ln (T P))$

$\operatorname{TLI}(\mathrm{TN})=10(5.453+1.694 \ln (\mathrm{TN}))$

$\operatorname{TLI}(C O D)=10\left(0.109+2.661 \ln \left(\operatorname{COD}_{M n}\right)\right)$

Equations 5, 6, and 7 are empirical regression equations based on a survey of eutrophication levels of water body in China, which based on the correlations between the index of the eutrophication and water quality parameters.

The obtained $T L I(\Sigma)$ was generally classified into five grades: $T L I(\Sigma)<30$ indicates oligotropher for the assessed district, $30<T L I(\Sigma)<50$ suggests mesotropher of contamination, $50<T L I(\Sigma)<60$ indicates light eutropher, $60<T L I(\Sigma)<70$ indicates middle eutropher and $T L I(\Sigma)>70$ represents hyper eutropher.

\section{Results}

In general, the variation trend of pollution contents in water samples declined from 2013 to 2015 and increased in the last two years. Among the pollutions, the concentrations of $C O D_{M n}$ at all sampling points were higher than $15.00 \mathrm{mg} \cdot \mathrm{L}^{-1}$ in five years, which were far beyond the national standard (GB3838-2002, China, Table 1). The content of $\mathrm{COD}_{\mathrm{Mn}}$ in Tashi area was basically the highest in five years. The highest growth rate of $\mathrm{COD}_{\mathrm{Mn}}$ from 2015 to 2017 was found in Tashi area and Sanjiang town, which 
were $48.21 \%$ and $47.04 \%$, respectively. Since there are more shrimp ponds in these two areas, the mariculture produced more organic matter. The contents of TN and AN from 2013 to 2015 were in the range of $0.45-1.22$ and $0.35-0.80 \mathrm{mg} \cdot \mathrm{L}^{-1}$, respectively. However, the content of TN had a rising trend since 2016. In particular, the contents of TN in Tashi area and Yanfeng town exceeded the standard limit of $1 \mathrm{mg} \cdot \mathrm{L}^{-1}$ (GB3838-2002, China, Table 1). The maximum values of these two regions were 1.41 and $1.22 \mathrm{mg} \cdot \mathrm{L}^{-1}$, respectively, in 2016 . Additionally, the content of TP had been always below the national standard limit of $0.2 \mathrm{mg} \cdot \mathrm{L}^{-1}$.

The contents of $\mathrm{Zn}, \mathrm{Cu}, \mathrm{Pb}$ and $\mathrm{Cd}$ were in the ranges of 8.72-24.66, 5.20-16.37, 2.61-5.93, 0.009-0.023 mg. $\mathrm{kg}^{-1}$, and with the means of $16.33,10.64,4.15,0.015 \mathrm{mg} \cdot \mathrm{Kg}^{-1}$, respectively. Compared to the upper limits in Class I sediment category (Zn $100 \mathrm{mg} \cdot \mathrm{Kg}^{-1}, \mathrm{Cu} 35 \mathrm{mg} \cdot \mathrm{Kg}^{-1}, \mathrm{~Pb}$ $60 \mathrm{mg} \cdot \mathrm{Kg}^{-1}, \mathrm{Cd} 0.5 \mathrm{mg} \cdot \mathrm{Kg}^{-1}$ ), derived from Environmental quality standard for sediment in the National Standard of China GB18668-2002), the contents of the four heavy metals in this study were far lower than the standard limits. The $\mathrm{pH}$ values of sediment samples showed a slow downward trend in the last five years and the minimum value was 5.63 in Tashi area in 2016. Since the use of disinfectants (hydrogen peroxide and chlorine dioxide) in shrimp farming and humus from dead mangroves, the average value of $\mathrm{pH}$ was less than 7.00 and weakly acidic.

On the basis of related monitoring data for five years, three kinds of pollution evaluation methods were used to analyze pollution situation and variation characteristics. Based on class III of Environmental quality standard for surface water (GB3838-2002, China, Table 2), the results of Single factor index (Fig. 4) showed that $\mathrm{COD}_{\mathrm{Mn}}$ was the most serious pollution, which was mostly $1 \sim 3$ times over the standard. Among the sampling areas, the Single factor index of $\mathrm{COD}_{\mathrm{Mn}}$ in Tashi always exceeded 3.5, which was the most serious pollution region. Meanwhile, the results of three single factor indexes of TN, AN, and TP were basically less than 1, which meant the contents of TN, AN, and TP in the water were largely lower than the standard limits from 2013 to 2015. During this period, although the nitrogen contents of a few sampling points exceeded the standard, the single factor indexes were below 1.2. However, the indexes of TN and AN in the water body increased significantly from 2016. And the highest indexes of TN and AN in the most polluted area of Tashi were 1.32 and 1.02, respectively.

According to Nemerow's pollution index (NPI), the comprehensive pollution index variation map of mangrove wetland in Dongzhai harbor was shown in Fig. 5. Compared with the Single factor index, the NPI can more clearly and intuitively reflect the comprehensive quality of water in the monitoring areas. The NPI highlights the influence of the most serious pollution factors and takes into account the other factors at the same time. From Fig. 5, the pollution in the mangrove wetland of Dongzhai harbor showed a significant reduction from 2013 to 2015 and there was an increasing trend since 2016. In 2013, the number of highly polluted sampling points in Dongzhai harbor was 12. Apart from three sampling points in Sanjiang town, NPI of all the other sampling points exceeded 3 . In 2015, the water quality was improved, 6 sampling points were moderately polluted, and the rest of the points were slightly polluted. However, the number of sampling points with moderate pollution reached 10 in 2016. The NPI of Tashi area was exceeded 3, and the NPI of Daoxue village and Sanjiang town exceeded 2 in 2017.

According to Trophic level index (TLI), the comprehensive trophic index variation map of mangrove wetland in Dongzhai harbor was shown in Fig. 6. The eutrophication of Dongzhai harbor had shown a trend from serious to mitigate and then began to deteriorate again. This change was basically the same as the variation trend of NPI in Fig. 5. In 2013, the number of hyper eutrophication sampling points in Dongzhai harbor was 10. In 2015, there were no hyper eutrophication sampling points and the middle eutrophication points were 5 . However, the eutrophication of Dongzhai harbor was serious again since 2016. In 2017, the sampling points of hyper and middle eutrophication were 4 and 9 , respectively. The areas with hyper eutrophication were Tashi area and Shanwei village.

\section{Discussion}

Mangroves located in Dongzhai harbor were polluted by non-point sources because of the shrimp culture. Based on satellite analysis and field investigation, by removing abandoned shrimp ponds, it was estimated that the area of shrimp ponds in Dongzhai harbor increased from about 1210 ha in 2009 to 1300 ha in 2017 within the $1.5 \mathrm{~km}$ buffer zone along the coastline [17]. The higher-place shrimp ponds needed a large amount of artificial feed for highdensity aquaculture, but the amount of nutrients added to the pond was only a few could translate into the biomass of shrimp, most nutrients flow into the surrounding mangrove wetlands along with the discharge of aquaculture wastewater [30]. Therefore, nitrogen and organic matter from the wastewater caused pollution and eutrophication in Dongzhai harbor, which affected the mangrove ecosystem. For example, in the past two years, pollution and eutrophication of Tashi area, Shanwei village, and Sanjiang town had been serious, especially organic matter and nitrogen pollution in the water body. Meanwhile, during the process of studying pollutants in Dongzhai harbor, it was found that there was a continuous degradation of 

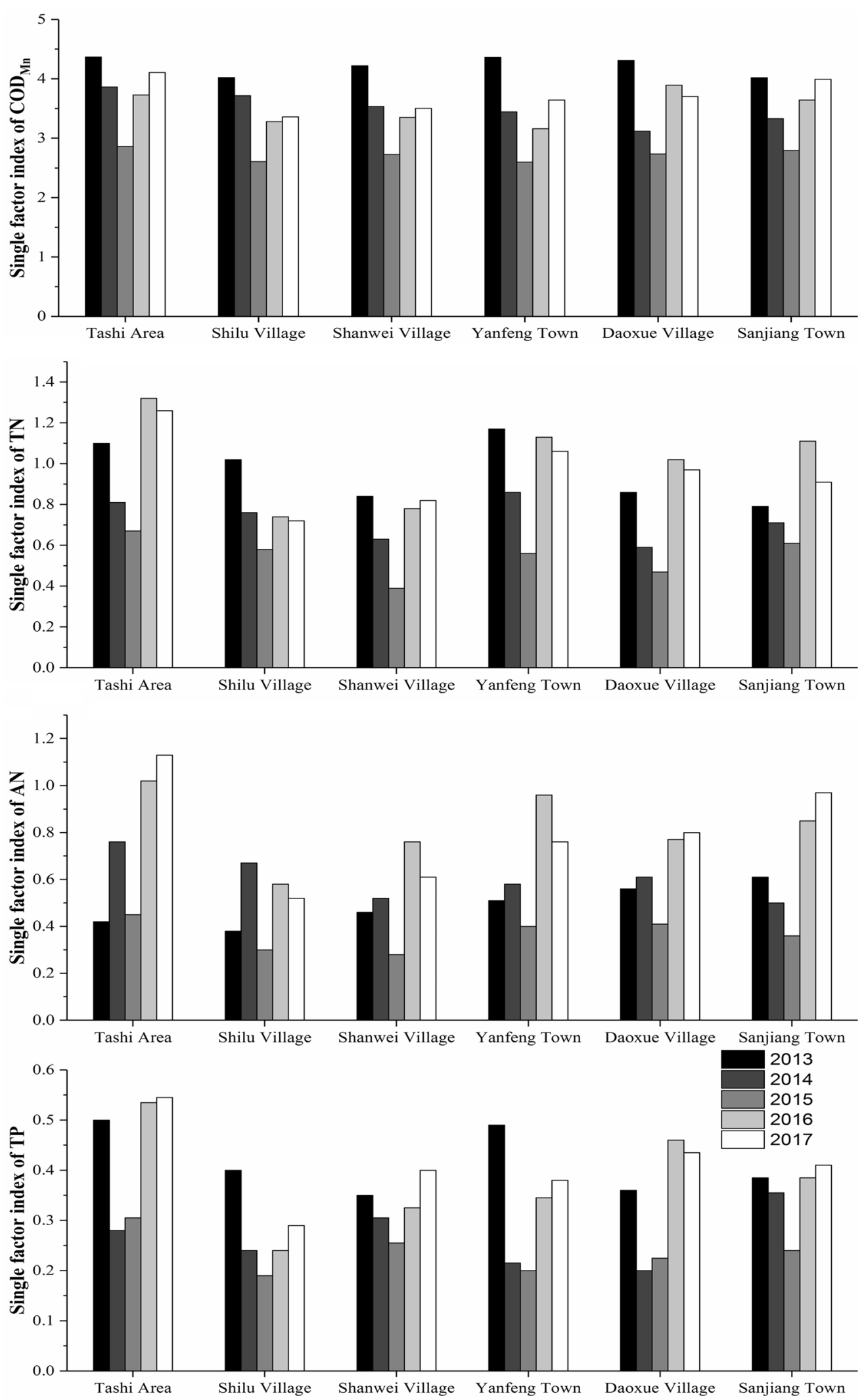

Sampling area

Fig. 4 Single factor indices of six regions from 2013 to $2017\left(C_{M n}, T N, A N, T P\right)$ 

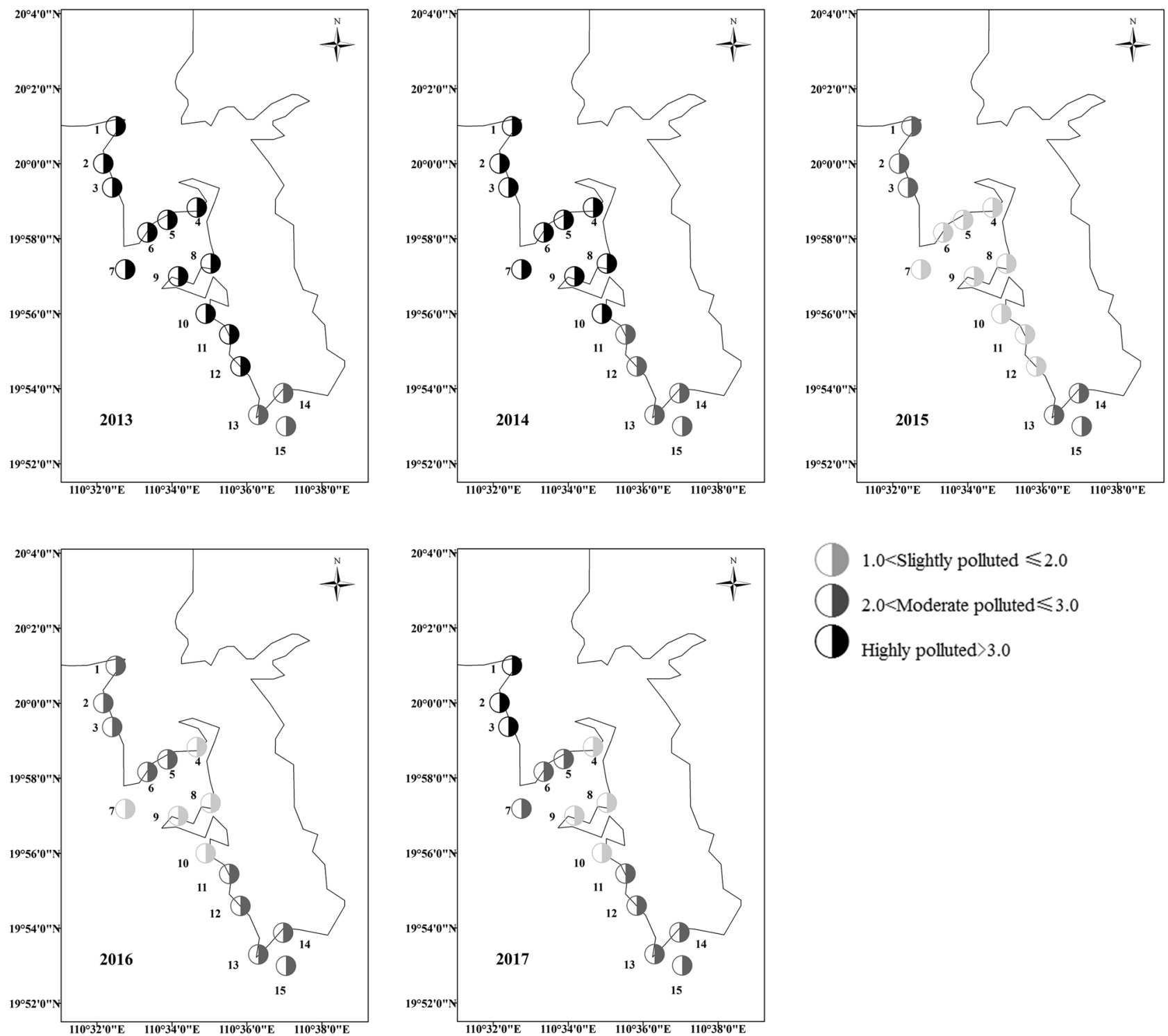

Fig. 5 Nemerow's pollution index for each sampling point along Dongzhai harbor from 2013 to 2017

mangroves. The mangrove was damaged by S. terebrans, which was distributed in the coastal areas suffering serious anthropogenic disturbance and contamination. For example, about 41 ha shrimp ponds are distributed around the Changning River $\left(110^{\circ} 34^{\prime} 7.17^{\prime \prime} \sim 110^{\circ} 35^{\prime} 14.62^{\prime \prime}\right.$ $\left.\mathrm{E}, 19^{\circ} 56^{\prime} 53.96^{\prime \prime} \sim 19^{\circ} 57^{\prime} 21.19^{\prime \prime} \mathrm{N}\right)$ and the area of mangrove degradation increased from 2.49 ha in 2013 to 7.62 ha in 2017 [17]. According to the monitoring data, Dongzhai harbor had no risk of heavy metal pollution in the past 5 years. This was because Hainan was the only area without industrial production in China and there were kelp culture in Dongzhai harbor. Due to kelp alga is one of the biosorption remediation technologies that has a strong removal effect of heavy metals in seawater [31], the kelp mariculture activities likely contributes, at least in part, to the lower metal contents in coastal sediments in Dongzhai harbor. Nevertheless, in view of seafood security and human health, continuous attention should be strengthened on the heavy metal pollution of Dongzhai harbor in the future.

Based on the monitoring indicators, the three water quality indexes basically showed the same trend of pollution variation, which was from serious to mitigate and then began to deteriorate again. According to the investigation for five consecutive years, a large outbreak of marine borers- $S$. terebrans occurred in the mangrove area of Dongzhai harbor in 2013, which caused the mangrove death. The reason for this outbreak was that eutrophic water would lead to the explosive growth of algae and plankton in the estuaries and mangrove wetlands. And 

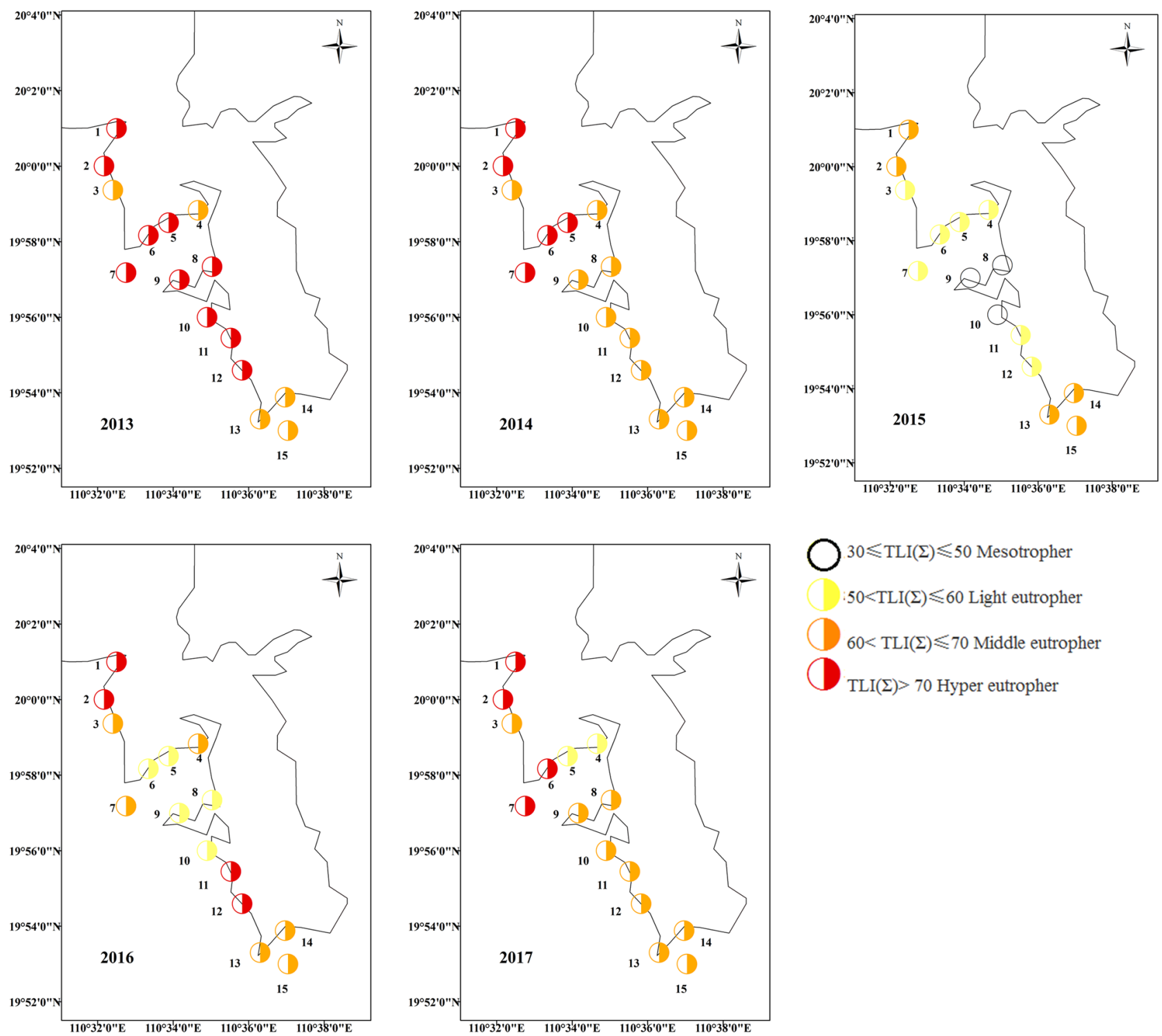

Fig. 6 Trophic level index for each sampling point along Dongzhai harbor from 2013 to 2017

plankton could provide rich food for the marine borers-S. terebrans, which would lead to a huge threat to mangroves $[32,33]$. Thus, the Haikou Municipal Government implemented pollution control measures since January 2014 and these measures had reduced the pollution in 2015. For example, Daoxue village was one of the regions that had the most intensive implementation of contamination abatement strategies. Half of the shrimp ponds in Daoxue village were closed in early 2014 and we could find a significant reduction of pollution and eutrophication in this region. Moreover, Yanfeng town, as one of the seriously polluted towns, also began to implement strict pollution control measures in late 2014. Half of the shrimp ponds in Yanfeng town were closed. At the same time, livestock farms were relocated and a matching pipe network was set up for sewage discharge from some shrimp ponds. Therefore, the amelioration of pollution was the most obvious in Yanfeng Town. In contrast, due to Tashi area and Sanjiang town only closed about one-eighth of shrimp ponds, the decreases of pollution and eutrophication were not obvious in Tashi area. And in Sanjiang town, the ranges of NPI and TLI were always $2-3,60-70$, respectively, which were moderately polluted and middle eutropher in five years. Meanwhile, Shilu and Shanwei village also began to manage shrimp culture at the end of 2014, about one-sixth of the shrimp ponds were closed and relevant departments collected the domestic sewage discharged. And as a result, pollution in these two areas had been reduced. However, with the control of S. terebrans outbreak and the weakening of supervision, the number of higher-place shrimp 
ponds around the mangroves had been increasing since 2016. Therefore, in the last two years, the pollution and eutrophication in the mangrove area of Dongzhai harbor had been serious again. The eutrophication of Tashi and Sanjiang town was deteriorating. And the pollution of organic matter and nitrogen in the water body was particularly serious. Additionally, compared with the data of 2013 that S. terebrans outbreak suddenly when the area of serious pollution and eutrophication was over two-thirds, the relevant departments should take measures to control the serious water pollution since 2016.

Therefore, the solution to this cultural problem is one of the keys to the restoration of mangrove ecosystem in the future. One of the major challenges faced by shrimp farming is to overcome environmental concerns and improve economic efficiency by developing and implementing management strategies that reduce nutrient wastes. We could find some new approaches, which include the improvements of feed formulation and the management of effluent treatment systems. The management and recovery of mangroves in Dongzhai harbor should be more integrated, standardized and strict. A complete mangrove ecological monitoring system should be established to grasp the dynamic changes of mangrove wetlands and analyze the causes. Meanwhile, in order to protect the coastal ecological environment strictly, the residents in the ecologically sensitive areas could gradually migrate to another livable place. On the basis of the coastal area restoration, the modern marine pastures could be vigorously developed to replace the higher-place shrimp ponds. Relevant departments should establish a total quantity control system for the pollutants entering mangrove wetland and formulate comprehensive plans for the protection and utilization of coastal zones.

\section{Conclusions}

The mangrove wetland is a high-yield ecosystem in the coastal ecosystem. Although coastal residents know its importance, the mangrove wetland in Dongzhai harbor, Hainan has been seriously threatened in the past 30 years. Therefore, a comprehensive analysis of effluents and heavy metals is necessary for Dongzhai harbor, considering the mangrove declined and the ecological services offered to the coastal communities. According to the monitoring results, due to shrimp culture, the contents of organic matter and nitrogen in the water of Dongzhai harbor were exceeding the standard, which were $26.10 \mathrm{mg} \cdot \mathrm{L}^{-1}$ and $1.34 \mathrm{mg} \cdot \mathrm{L}^{-1}$, respectively in 2017 . The contents of the four heavy metals ( $\mathrm{Cu}, \mathrm{Pb}, \mathrm{Zn}, \mathrm{Cd})$ were far lower than the standard limits during the past five years. On the basis of monitoring indicators, three water quality indexes basically showed the same trend of pollution variation, which showed a significant reduction from 2013 to 2015 and then there was an increasing trend since 2016. Single factor index, Nemerow's pollution index, and Trophic level index revealed that the heavily polluted areas were Tashi and Sanjiang town. Furthermore, since compared with the data of 2013, S. terebrans outbreak suddenly when the area of serious pollution and eutrophication was over two-thirds, there should be restoration activities to control the water pollution since 2016. The discharge of untreated aquaculture wastewater has brought tremendous pressure to the ecological environment of mangrove wetland in Dongzhai harbor. Hence, it is imperative to devise longterm management and conservation plans for the ecologically significant mangrove forests with a focus on sustainable livelihood.

Acknowledgements The authors would like to thank the colleagues from Dongzhai harbor Environmental Protection Center for their help during field work. This work was supported by the Global Environment Facility (Hainan wetland protection system program), Special project for public welfare, China (20150413).

\section{Declarations}

Conflict of interest On behalf of all authors, the corresponding author states that there is no conflict of interest. Liu Jing and Myat Thiri have no conflict of interest.

Ethical approval statement This article does not contain any studies with human participants or animals performed by any of the authors. In this experiment, we did not collect any samples of human and animals.

Open Access This article is licensed under a Creative Commons Attribution 4.0 International License, which permits use, sharing, adaptation, distribution and reproduction in any medium or format, as long as you give appropriate credit to the original author(s) and the source, provide a link to the Creative Commons licence, and indicate if changes were made. The images or other third party material in this article are included in the article's Creative Commons licence, unless indicated otherwise in a credit line to the material. If material is not included in the article's Creative Commons licence and your intended use is not permitted by statutory regulation or exceeds the permitted use, you will need to obtain permission directly from the copyright holder. To view a copy of this licence, visit http://creativecommons. org/licenses/by/4.0/.

\section{References}

1. Garvis SK, Sacks PE, Walters LJ (2017) Formation, movement, and restoration of dead intertidal oyster reefs in canaveral national seashore and mosquito lagoon. Florida J Shellfish Res 34(2):251-258

2. Long J, Giri C, Primavera J, Trivedi M (2016) Damage and recovery assessment of the Philippines' mangroves following Super Typhoon Haiyan. Mar Pollut Bull 109(2):734-743 
3. Cannicci S, Burrows D, Fratini S, lii T, Offenberg J (2008) Faunal impact on vegetation structure and ecosystem function in mangrove forests: a review. Aquat Bot 89(2):186-200

4. Kathiresan K, Bingham BL (2001) Biology of mangroves and mangrove ecosystems. Adv Mar Biol 40(1):81-251

5. Valiela I, Bowen JL, York JK (2001) Mangrove forests: one of the world's threatened major tropical environments. Bioscience 51(10):807-815

6. Kruitwagen G, Pratap HB, Covaci A, Wendelaar Bonga SE (2008) Status of pollution in mangrove ecosystems along the coast of Tanzania. Marine Pollut Bull 6(5):1022-1031

7. Gilman E (2007) Efficacy of alternative low-cost approaches to mangrove restoration. Am Samoa Estua Coasts 30(4):641-651

8. lii R (2005) Ecological engineering for successful management and restoration of mangrove forests. Ecol Eng 24(4):403-418

9. Alongi DM (2008) Mangrove forests: Resilience, protection from tsunamis, and responses to global climate change. Estuar Coast Shelf Sci 76(1):1-13

10. Ellison JC (1993) Mangrove retreat with rising Sea-level, bermuda. Estuar Coast Shelf Sci 37(1):75-87

11. Costanzo SD, O'Donohue MJ, Dennison WC (2004) Assessing the influence and distribution of shrimp pond effluent in a tidal mangrove creek in north-east Australia. Mar Pollut Bull 48(5):514-525

12. Robertson Al, Phillips MJ (1995) Mangroves as filters of shrimp pond effluent: predictions and biogeochemical research needs. Hydrobiologia 295(1-3):311-321

13. Anh PT, Kroeze C, Bush SR, Mol APJ (2010) Water pollution by intensive brackish shrimp farming in south-east Vietnam: causes and options for control. Agric Water Manage 97(6):872-882

14. Li CH, Wei XL, Jie XY, Li Q, Hu WA (2011) Study on culture of comparative analysis under the different recycling rates of water in higher place shrimp pond. Guangdong Agric Sci 38(17):91-95

15. Li JL, Chen XF, Lai QM, Lu CY (2010) Study on nitrogen and phosphorus budgets and production performance in higherplace pond of Litopenaeus vannamei. South China Fish Sci 06(5):13-20

16. The Bureau of Statistics of Hainan Province, available from (2013)

17. Fan HQ, Liu WA, Zhong CR, Ni X (2014) Analytic study on the damages of wood-boring isopod, Sphaeroma, to China mangroves. Guangxi Sci 21(2):140-146

18. Casillas HR, Magallón BF, Portillo CG, Paez OF (2006) Nutrient mass balances in semi-intensive shrimp ponds from Sonora, Mexico using two feeding strategies: Trays and mechanical dispersal. Aquaculture 258(1-4):289-298

19. Bryan GW, Langston WJ (1992) Bioavailability, accumulation and effects of heavy metals in sediments with special reference to United-Kingdom estuaries: a review. Environ Pollut 76:89-131

20. Li H, Kang X, Li X, Li Q, Song J, Jiao N, Zhang Y (2017) Heavy metals in surface sediments along the Weihai coast, China:
Distribution, sources and contamination assessment. Mar Pollut Bull 115(1-2):551-558

21. Lin PS, Li S, Li BS, Zheng YH (2005) Correlativity between L and desertification and climate variability in West of Hainan Island during past nearly 20 years. J Desert Res 1:27-32

22. Zou HP, Zhang JH, Chen XM, Liu SJ, Li WG (2015) Spatiotemporal change characteristics of agricultural climate resources in Hainan Island. Chin J Agrometeorol 36(04):417-427

23. Liao BW, Li M, Zheng S, Chen Y, Zhong C (2005) Niches of several mangrove species in Dongzhai Harbor of Hainan Island. Chin J Appl Ecol 16(3):403-407

24. Wu R, Chen DD, Wang DR, Chen XH (2016) Survey of mangrove resources in Dongzhai harbor. Hainan Province Tropic Agric 36(9):62-65

25. Kotlash AR, Chessman BC (1998) Effects of water sample preservation and storage on nitrogen and phosphorus determinations: implications for the use of automated sampling equipment. Water Res 32(12):3731-3737

26. Lasorsa BM, Casas A (1996) A comparison of sample handling and analytical methods for determination of acid volatile sulfide in sediment. Mar Chem 52:211-220

27. Cao L, Li WP, Chen QL, Zhang CS (2017) The improved Nemerow Index and Fuzzy Mathematics method to evaluate the wetland water quality and its application comparison. Hubei Agric Sci 56(22):4278-4281

28. Kucuksezgin F, Kontas A, Altay O, Uluturhan E, Darilmaz E (2006) Assessment of marine pollution in Izmir Bay: heavy metal and total hydrocarbon concentrations. Environ Int 32(1):41-51

29. Parparov A, Gal G, Hamilton D (2010) Water quality assessment, trophic classification and water resources management. J Water Resour Prot 2(10):907-915

30. Funge-Smith SJ, Briggs MRP (1998) Nutrient budgets in intensive shrimp ponds: implications for sustainability. Aquaculture 164(1-4):117-133

31. Salman AA, Andres Y, Gerente C, Claire G, Pierre LC (2009) Natural seaweed waste as sorbent for heavy metal removal from solution. Environ Technol 30(7):755-762

32. Brooks RA, Bell SS (2005) The distribution and abundance of Sphaeroma terebrans, a Wood-boring Isopod of Red Mangrove (Rhizophora mangle) Habitat within Tampa Bay. Bull Mar Sci 76(1):27-46

33. Svavarsson J, Osore MKW, Olafsson E (2002) Does the woodborer Sphaeroma terebrans (Crustacea) shape the distribution of the mangrove Rhizophora mucronata? Ambio 31(7/8):574-579

Publisher's Note Springer Nature remains neutral with regard to jurisdictional claims in published maps and institutional affiliations. 